\title{
Influence of the calendering step on the adhesion properties of coextruded
}

\section{structures}

M.C.Serrat*,**, J.F.Agassant* , J.Bikard*, S.Devisme**

* MINES-Paristech, CEMEF, UMR CNRS 7635, BP 207, 06904 Sophia-Antipolis, France **, Arkema, Cerdato Research Center ,27470, Serquigny, France

\section{Abstract}

The coupled coextrusion calendering process of multilayer thermoplastic sheets has been studied. The structure of the film has been observed, the density of chemical links at the interface and the adhesion between the coextruded layers have been measured. There are some controversial features about the influence of calendering parameters. Several models of increasing complexity are proposed to master the process and its influence on adhesion. A multilayer thermal model accounting for the crystallization kinetics of both polymers allows defining qualitatively the temperature field especially at the interface between the two layers. A multilayer thermo- mechanical model provides quantitative figures on the stress, shear, elongation and temperature fields in the coextruded film and especially at the interface. Relationships between these parameters, density of chemical links at the interface, crystalline structure of the sample and peeling forces are discussed.

Keywords: multilayer film, calendering, modelling, finite elements, adhesion

\section{Introduction}

Many thermoplastic sheets for packaging applications are composed of several layers of different thermoplastics, which allow combining optical, mechanical and organoleptic properties. We consider here a specific product constituted by a thick $(450 \mu m)$ homopolymer polypropylene layer (Total Petrochemicals), a thin (50 $\mu \mathrm{m})$ polyamide 6 layer (Ultramid B3 
from BASF) and, in-between, a tie layer (10 to $20 \mu \mathrm{m})$ constituted by an anhydride maleic modified polypropylene provided by ARKEMA.

These thermoplastic sheets are produced by combining a classical coextrusion device and a two-roll calender (Figure 1). The coextrusion device is made up of several extruders (a), a fixed feedblock where the three different polymers are brought together (b) and a classical coat hanger die which delivers a sheet of uniform thickness (c). The coextruded sheet is then stretched (d) at a low draw ratio (around 5) between the die and the rolls (e). The final film thickness and to a certain extent the adhesion between the different layers can be controlled by the two-roll calender. Mastering the different steps of this coextrusion-calendering process is a difficult task: the flow rate delivered by the coextrusion device needs to be equivalent to the calendering rate and this requires complex adjustments.

The mechanisms which govern adhesion between modified polypropylene and polyamide are twofold:

- the copolymerization chemical reaction at the interface between maleic anhydride grafted polypropylene and the amine groups of polyamide 6. It will start in the feedblock where the different polymers are brought together, continue in the coat-hanger die, then along the stretching path between the die exit and the calender, and finally in the calender nip itself, till solidification of the interface,

- the development of a crystalline structure on both sides of the interface which will be governed by the stretching step and the solidification step in the calender nip.

Both mechanisms are governed by the thermo-mechanical history all along the process and especially around the interface between the two layers.

In this paper we will investigate specifically the influence on the calendering step on adhesion. As far as we know, there is no published paper on that subject. The parameters which are supposed to influence adhesion are the followings: the rotation velocity of the rolls, 
the gap between the two rolls (but, in fact, this gap is a priori defined by the target thickness of the packaging sheet application), the temperature of the calender rolls (between ambient temperature and $80{ }^{\circ} \mathrm{C}$ ), but also the size of the reservoir (often called the bank in the

calendering literature) upstream the calender nip. This last parameter is difficult to control and is a result of the adjustment of the calendering parameters to the coextrusion parameters.

In the next section of this paper, the influence of several calendering parameters on the peeling force between the different layers, on the density of chemical links at the interface as measured by X-ray photoelectron spectroscopy and on the crystalline structure of the samples will be investigated. In the second section, several thermal or thermo-mechanical models of the calendering process will be developed. In the last part of the paper, some correlations between the experimental results and the models will be discussed.

\section{Experiments}

In all experiments, the thickness of the coextruded structure is kept constant $(500 \mu m)$ as well as the extrusion temperature $\left(230^{\circ} \mathrm{C}\right)$ and the calender roll temperature $\left(30^{\circ} \mathrm{C}\right)$. Two line speed were tested ( 2 and $5 \mathrm{~m} / \mathrm{min}$ ) meaning that velocity of the different extruders and the rolls velocities have been varied simultaneously. This is a difficult task: if the extrusion rate is more important than the calender rate, the size of the bank will increase progressively and finally one part of the polymer will escape on each side of the rolls; if the extrusion rate is less important than the calender rate the bank will disappear. We will explain in paragraph 2 why the processing window is in fact broader. At the end of each run, the gap between the two rolls is open in order to compare the properties of the coextruded sheet produced in a calendering process and in a cast film process. In all experiments, a small bank has been maintained (a ratio of three between the bank thickness and the gap between the two rolls, which is very small when compared to the classical calendering situations). 


\section{Adhesive strength measurement}

The adhesive strength at the interface tie layer/PA6 was measured using a free peel test (Figure 2) which geometry is controlled by the relative bending rigidity of the peeling arms and their thicknesses. Peeling test at room temperature $\left(25^{\circ} \mathrm{C}\right)$ was performed with an Instron tensile machine using a crosshead speed of $200 \mathrm{~mm} / \mathrm{min}$ and a $100 \mathrm{~N}$ load cell. The angle between the two strips is around $180^{\circ}$. For each process conditions, the adhesive strength was measured three times for reproducibility. The mean peel force was then considered (standard deviation $<0.1-0.2 \mathrm{~N})$.

The experimental results show that line speed can affect peel strength (Figure 3). However the effect of calendering is not evident as opening the nip (which means that the process is now equivalent to cast film) does not influence adhesion at low roll velocity, and only slightly decreases adhesion at high velocity.

\section{Density of chemical links at the interface}

The chemical reaction between maleic anhydride grafted polypropylene and the amine chain ends of polyamide 6 can be followed by measuring the density of copolymer $(\Sigma)$ at the interface. A protocol originally developed by Boucher et al. (1996) was used. This method is based onto dissolution of the PA6 part of the multilayered film with three baths of formic acid, followed by a treatment with trifluoroacetic anhydride in the gas phase and a hydroxylation in deionised water. The amount of PA6 remaining on the PP film was quantified by XPS (X-ray Photoelectron Spectroscopy) through the nitrogen/carbon ratio. The

XPS spectra were collected on a SSX-100 Surface Science spectrometer using a monochromatic source $\left(\mathrm{Al} \mathrm{K} \mathrm{K}_{\alpha 1}, \mathrm{hv}=1486.6 \mathrm{eV}\right)$. The 1s spectra of carbon and nitrogen were then recorded on a clean area of the sample and used to estimate $\Sigma$ through : 


$$
\sum=\frac{N_{A} \rho \lambda \sin \theta}{M_{n}} \ln \left(1-\frac{I_{N} / I_{C}}{\left(I_{N} / I_{C}\right)^{\infty}}\right)
$$

$N_{A}$ is the Avogadro's number, $\rho$ the mass density of PA6, Mn its number average molecular weight, $\lambda$ the mean free path of $\mathrm{N} 1 \mathrm{~s}$ photoelectrons, and $\theta$ the takeoff angle $\left(35^{\circ}\right) . I_{C}, I_{N}, I^{\infty}{ }_{C}$, and $I_{N}^{\infty}$ are the intensities of the carbon and nitrogen peaks for the analysed sample and for pure PA6 film respectively. The reproducibility of the $\Sigma$ determination was approximately $\pm 10 \%$. In addition, the molecular characteristics of both PP and PA6 impose a saturation grafting density, which is close to $\Sigma_{\mathrm{sat}} \sim 0,08 \mathrm{ch} / \mathrm{nm}^{2}$ in the case of this study (Bondil, 2006; Barraud, 2009).

Figure 4 shows the plot of $\Sigma$ as a function of line speed. The density of the chemical links seems to depend only on the technology used (calendering/ cast) and not on the processing parameters. We can also notice that these results are always lower than the maximum saturation level $\left(\Sigma_{\text {sat }}\right)$ as expected.

It is now possible to express (from Figures 3 and 4) the peeling force as a function of the density of chemical links (Figure 5). There is no clear correlation between these two measurements contrarily to what has been observed by Devisme et al. (2009) for a polypropylene/aluminium multilayered system made by extrusion coating.

\section{Crystallinity and optical microscopy}

Optical microscopic observations of thin slices of the different coextruded sheets within the thickness have been done at Arkema Cerdato research centre. In addition, X-Ray diffraction measurements have been made in the middle of the polypropylene layer in order to determine the crystallinity ratio: in all the samples, we do not observe any structure within the polyamide layer but we can distinguish clearly the morphology (essentially spherulitic) in the tie layer and in polypropylene.

At a roll velocity of $2 \mathrm{~m} / \mathrm{min}$, crystallinity is high (45\%) and spherulites are small (5 $\mu \mathrm{m}$ around the interface and smaller elsewhere) (Figure 6). When opening the calender, 
crystallinity remains high $(30 \%)$ with spherulites smaller but more homogeneous in size (Figure 7).

At higher roll velocity $(6 \mathrm{~m} / \mathrm{min})$ crystallinity is less important $(25 \%)$, the size of the spherulites is larger and heterogeneous in size (Figure 8a global picture, and Figure 8b inner core of the polypropylene layer). When the calender is open, crystallinity remains low (26\%), large spherulites may be observed, some of them as big as $30 \mu m$ (Figure 9).

In fact one would expect for high crystallinity with large spherulites and low crystallinity with small spherulites. Further investigations need to be performed at varying pressures and cooling rates to provide possible explanations.

We will propose successive models of the calendering process, in order to try to explain the different experimental results.

\section{Modelling of the calendering process}

The early calendering models have been developed for the rubber and PVC industry (Ardichvilli, 1938; Mc Kelvey, 1962; Kiparissides and Vlachopoulos, 1976; Agassant and Avenas, 1977). They used Newtonian or shear thinning behaviour and considered a 2D symmetric flow in the nip. Using the so-called "lubrication approximations" they obtained the velocity field between the rolls and the pressure distribution. Mitsoulis et al.(1985) and Agassant and Espy (1985) computed the stationary non-symmetric velocity field within the bank using finite element methods. This 2D computation points out the existence of complex recirculating cells in the bank but, in the nip region, the flow remains symmetric. This $2 \mathrm{D}$ computation has been extended later by Luther and Meves (2004) to account for the real 3D flow. This allows the prediction of the sheet widening within the nip, but this is not of prime importance for the kinematics and stress prediction in the nip. For that reason we will develop only 2D models (see Figure 10). Papanastasiou et al.(1992) and more recently Carvalho and 
Svriven (1997) have modelled the flow between the cylinders by postulating an initial geometry (with an initial shape of the bank of polymer) and used it as a control volume for finite element calculations. The last authors take into account the interfacial tension on free surfaces in contact with air and solve the Navier-Stokes equations inside the control volume. Then the mesh is adapted during the calculation steps to simulate the development of the bank.

All the authors assume that the sheet will leave the calender nip when the velocity throughout the thickness is uniform. This means that the final sheet thickness at calender outlet is larger than the minimum gap between the two rolls. This "spread height" is independent of the roll velocity (when the rotation velocity of the two rolls is the same), is only slightly dependent on the polymer rheology, but varies with the size of the bank especially when it is small (Agassant et al, 1977). The pressure distribution and the roll separating force will vary with the roll velocity, the rheology of the polymer and the size of the bank.

These models explain qualitatively why it is possible to run a coupled coextrusion / calendering line within a reasonable "processing window". At a first glance, one may believe that there is only one set of calendering parameters for each flow rate distribution of the different extruders. In fact, if one increases the extrusion rates, the calender bank will increase progressively and so the spread height, which means the calender output which is proportional to the roll rotation velocity and to the spread height; simultaneously, the pressure will be more important, which results in a deflection of the rolls and of the frame of the calender, and this again increases the output; in addition, the more important is the bank size, the more important is the sheet widening in the contact and this again contributes to increase the calender output. 
But these models do not take into account the strong thermo-mechanical coupling taking place during the process especially because of the strong temperature gradient between the polymer inlet temperature and the roll temperature. Therefore, we first propose a multilayer purely thermal model in an equivalent geometry and then a complete $2 \mathrm{D}$ multilayer thermomechanical laminar model.

\section{Multilayer thermal model}

In order to capture the crystallisation time as well as the thermal history along the process and especially at the interface, we used the software THERM developed at Cemef, (Cotto et al., 1989, Duffo et al., 1991, Devisme et al., 2007) which accounts for multilayer structures and the crystallization kinetics of the different polymers. We assume that the copolymerization chemical reaction at the interface is completely stopped or enough slowed down when the two polymers started to crystallize (Bondil et al, 2006, Barraud, 2009). The problem is solved in two steps: In the air gap, the crystallization is neglected when the polymer is stretched in air due to the high temperature and only the mechanical equations are taken into account. In contact with the calender, only the energy equation is solved as we neglect the thickness reduction. An equivalent geometry (Figure 11) is built to the real processing geometry of Figure 10. Gravity, inertia forces and surface tension are neglected, and the cross section of the film is assumed to remain rectangular. The polymer melt is considered as a Newtonian fluid.

The mechanical equations along the stretching distance are in a cartesian coordinate system:

- a constant stretching force: $F_{0}=e(x) \cdot 1(x) \cdot \sigma_{x x}(x)$

- a constant volume flow rate: $\mathrm{q}=\mathrm{e}(\mathrm{x}) \cdot \mathrm{l}(\mathrm{x}) \cdot \mathrm{u}(\mathrm{x})$ 
$\mathrm{e}, 1$ and $\mathrm{u}$ are respectively the film thickness the film width and the film velocity which vary along the stretching distance x. $\sigma_{x x}$ is the elongation stress.

- the Newtonian constitutive equation: $\sigma_{x x}=2 \eta\left(\frac{2 u^{\prime}}{u}+\frac{l^{\prime}}{l}\right)$ where $u^{\prime}=\frac{d u}{d x}$ and $l^{\prime}=\frac{d l}{d x}$

with the following boundary conditions: the die gap $\mathrm{e}_{0}$, its width $2 \mathrm{~L}_{0}$, the extrusion velocity $\mathrm{u}_{0}$ and the take-up velocity $\mathrm{U}$.

Crystallisation, which depends on the elongation rate between extrusion die and calender and on the cooling rate in the calender itself, is introduced in the model according to the Ozawa's method. It is assumed that the copolymerization chemical reaction at the interface is completely stopped or enough slowed down when the two polymers started to crystallize (Bondil et al, 2006, Barraud, 2009). The energy equation writes in the calendar nip and further, along the bottom roll (see Figure 11):

$$
U \frac{\partial \mathrm{T}(\mathrm{x}, \mathrm{z})}{\partial \mathrm{x}}=\mathrm{a} \frac{\partial^{2} \mathrm{~T}(\mathrm{x}, \mathrm{z})}{\partial \mathrm{z}^{2}}+U \frac{\Delta \mathrm{H}}{\mathrm{C}_{\mathrm{p}}} \frac{\partial \alpha(\mathrm{x}, \mathrm{z})}{\partial \mathrm{x}}
$$

where $\alpha$ is the transformed volume fraction, $\mathrm{C}_{\mathrm{p}}$ is the heat capacity and $\Delta \mathrm{H}$ is the heat of crystallization per unit mass. It depends on the final crystallinity $\chi_{\mathrm{f}}: \Delta \mathrm{H}=\chi_{\mathrm{f}} \Delta \mathrm{H}_{0}$ where $\Delta \mathrm{H}_{0}$ is the theoretical enthalpy of crystallization per unit mass. The transformed volume fraction of the polymer can be expressed by the following equation (Cotto et al., 1989, Billon et al., 1991):

$$
\alpha(\mathrm{t})=1-\exp \left(-\frac{\chi(\mathrm{T})}{|\dot{\mathrm{T}}|^{n}}\right)
$$

where $\dot{\mathrm{T}}$ is the local cooling rate, $\mathrm{n}$ is the Avrami exponent and $\chi(\mathrm{T})$ the function defined by Ozawa.

Assuming as a first approximation that stretching has the same effect as shearing leads to the following equations:

$$
\ln (\chi(\mathrm{T}, \dot{\alpha}))=\ln (\chi(\mathrm{T}))_{\mathrm{DSC}}+\mathrm{f}(\dot{\alpha})
$$


with : $\quad \ln (\chi(\mathrm{T}))_{\mathrm{DSC}}=\mathrm{A}+\mathrm{BT}+\mathrm{CT}^{2}+\mathrm{DT}^{3}+\mathrm{ET}^{4}$

and: $\quad f(\dot{\alpha})=3 \ln \left(1+\mathrm{q} \dot{\alpha}+\dot{r}^{2}\right)$

where $\dot{\alpha}$ is an approximate value of the elongation rate $\left(\dot{\alpha}=\frac{u-u_{0}}{\mathrm{X}}\right), \mathrm{A}, \mathrm{B}, \mathrm{C}, \mathrm{D}$ and $\mathrm{E}$ are coefficients obtained from a polynomial fitting. $\mathrm{q}$ and $\mathrm{r}$ are dependent on molecular weight. The Avrami exponent $\mathrm{n}$ is taken equal to 3. All the data used in this study were taken from the work of Devisme et al., 2007.

Varying thermal boundary conditions are applied: in the entry zone $\mathrm{B}$, the temperature of the bottom roll $\left(30^{\circ} \mathrm{C}\right)$ is imposed along the polyamide 6 interface and a heat transfer coefficient along the upper surface $\left(h_{T}=10 \mathrm{~W} / \mathrm{m}^{2} \mathrm{~K}\right.$ which corresponds to classical values in free convection at polymer/air interface); in the contact zone $\mathrm{C}$ (which length will depend on the bank size ) the temperature of both rolls $\left(30^{\circ} \mathrm{C}\right)$ is fixed; in the exit zone $\mathrm{D}$, the temperature of the bottom roll is again imposed on one side and the same heat transfer coefficient as in zone B on the other side. The initial temperature at the inlet of zone B is constant and equal to the extrusion temperature $\left(230^{\circ} \mathrm{C}\right)$. Equations (1-5) are solved using an explicit finite difference method.

The temperature traces along the bottom roll, the upper roll and at the interface between polyamide 6 and polypropylene (tie layer) are presented on Figure 12 when the roll velocity is $2 \mathrm{~m} / \mathrm{min}$. Polyamide 6 (which is located at the bottom) will crystallize in its whole thickness as soon as it is in contact with the lower roll, which means even before entering the calender nip (at such a high cooling rate, the crystallization temperature of polyamide 6 is around $160^{\circ} \mathrm{C}$ ); polypropylene will crystallize at the interface after a few millimetres in the calender nip; the upper surface of the coextruded sheet will crystallize within the nip, but then its temperature will increase again, even if no remelting may be observed. It is to notice that an important fraction of the polypropylene layer remains in the molten state at the nip exit. As a 
consequence, it will be subjected to a "squeezing flow" in the third direction between the two rolls.

When opening the calender, which means that there is no calendering any more and the process is equivalent to cast film, the crystallization kinetics will be identical in the polyamide layer and at the interface with polypropylene, but the upper surface of the coextruded sheet will crystallize on a much longer distance. In that situation, there is no "squeezing flow".

When increasing the roll velocity to $6 \mathrm{~m} / \mathrm{min}$ (Figure 13), polyamide crystallizes again as soon as it is in contact with the roll, polypropylene will crystallize at the interface on a longer distance $(10 \mathrm{~mm})$, the upper surface of the coextruded sheet does not crystallize at nip exit, and then its temperature will increase again. Most of the polypropylene layer will remain in the molten state at nip exit and crystallization will be completed only after a long distance on the bottom roll $(150 \mathrm{~mm})$.

One can draw the following conclusions from this multilayer thermal model: the temperature profile at the interface between polyamide and polypropylene is the same when the calender is closed or open (cast-film condition). Polyamide crystallizes completely as soon as it is in contact with the bottom roll in all processing situations. As a consequence chemical reactions will be blocked at the interface on the polyamide side at the calender inlet. Polypropylene will crystallize at the interface within the calender nip, on a distance which depends on the roll velocity and the copolymerization reaction can continue along the interface, even at a low rate, till solidification. The coextruded film will never been totally solidified at the nip exit, but the temperature field will be significantly influenced by the processing parameters (roll velocity, calender closed or open). As a consequence, the crystalline structure will depend of these parameters. 
This multilayer thermal model does not account for the strains and stresses which develop within the calender nip and influence both the chemical reactions and the crystallization mechanisms.

\section{Multilayer temperature dependent mechanical model}

We develop an incremental 2D finite element computation model based on a Lagrangian description (Fourment and Chenot, 1994, Pichelin et al., 1998, Fourment et al., 1999) using FORGE2 software in the geometry summarized in Figure10. As a difference with the Eulerian description (assuming an initial geometry of the bank, see Mitsoulis et al. (1985), Agassant and Espy (1985), Arnold et al.(1984), Béraudo et al.(1997) ), the main interest of Lagrangian approach lies in the exact description of the motion of interfaces. In this way, the development of the bank and of the spread height will be the result of the mechanical balance in the calendering process and not an a priori hypothesis.

At time $\mathrm{t}=0$ the molten polymer in the die (left on Figure 10) is pushed at a constant rate, it flows progressively out of the die, falls on the bottom roll and then is pulled into the calender gap by the rotation velocity of the rolls. A very high friction coefficient is imposed along the surface of both rolls so that the surface velocity of the polymer is equal to the rotation velocity of the rolls $\left(\mathrm{v}=\mathrm{V}_{\text {roll }}\right.$, as proposed by Carvalo and Scriven (1997)). The bank will develop progressively and the point where the coextruded film will leave the upper roll at nip exit is a result of the computation. For some processing parameters the bank size will stabilize and we stop the incremental computation when the pressure distribution does not change any more (Figure 15). For some other processing parameters (when the extrusion rate is significantly higher than the product of the gap thickness by the mean rotation velocity of the rolls and the sheet width), the bank will grow continuously and the pressure peak will never stabilize. 
Assuming the polymer as an incompressible fluid, the mechanical and temperature balance equations in each phase can be written by (we denote by $\_$the interface between each polymer

$\underline{\operatorname{div} \mathbf{v}=0 \quad \text { in both polymers }}$

$\operatorname{div} \sigma_{1}+\rho_{1} g=0 \quad$ in polymer 1

$\operatorname{div} \boldsymbol{\sigma}_{2}+\rho_{2} g=0 \quad$ in polymer 2

$\underline{\sigma_{1} n=\sigma_{2} n} \quad$ along $\underline{\Gamma}$

$\rho_{1} c_{1} \dot{T}=\nabla .\left(k_{1} \nabla T\right)+\eta_{1}(\dot{\bar{\gamma}}, T) \dot{\bar{\gamma}}^{2} \quad$ in polymer 1

$\rho_{2} c_{2} \dot{T}=\nabla \cdot\left(k_{2} \nabla T\right)+\eta_{2}(\dot{\bar{\gamma}}, T) \dot{\bar{\gamma}}^{2}$ in polymer 2

$\phi=-k \nabla T . \mathbf{n}=h_{T}\left(T-T_{\text {roll }}\right) \quad$ along each calender roll and free surface

$k_{1} \nabla T . \mathbf{n}=k_{2} \nabla T . \mathbf{n} \quad$ along $\underline{\Gamma}$

$\boldsymbol{\sigma}_{1}=2 \eta_{1}(\dot{\bar{\gamma}}) \dot{\boldsymbol{\varepsilon}}_{1}(v)-p \mathbf{I} \quad$ constitutive equation for polymer 1

$\boldsymbol{\sigma}_{2}=2 \eta_{2}(\dot{\bar{\gamma}}, T) \boldsymbol{\varepsilon}_{2}(v)-p \mathbf{I} \quad$ constitutive equation for polymer 2

$\mathbf{V}$ is the velocity field, $\sigma_{1}$ and $\sigma_{2}$ are the stress tensors, $\mathrm{p}$ is the pressure, $\dot{\bar{\gamma}}$ is the second invariant of the rate of strain tensors $\dot{\varepsilon}_{1}$ and $\dot{\varepsilon}_{2}, \eta_{1}$ and $\eta_{2}$ are the viscosities of both polymers which follow a temperature dependent Carreau law.

$\eta=\eta_{0}(T)\left(1+(\lambda \dot{\bar{\gamma}})^{a}\right)^{\frac{n-1}{a}}$

$\mathrm{n}, \lambda$ and $a$ are fitting parameters, $\eta_{0}$ is the viscosity at the Newtonian plateau which depends on temperature following an Arrhenius law :

$\eta_{0}(T)=\eta_{0}\left(T_{0}\right) \exp \left(\frac{E}{R}\left(\frac{1}{T}-\frac{1}{T_{0}}\right)\right)$

$\mathrm{E}$ is the activation energy, $\mathrm{R}$ the gaz constant and $T_{0}$ is the reference temperature. 
$T$ is the temperature field, $\rho_{1}$ and $\rho_{2}$ are the densities, $C_{1}$ and $C_{2}$ the mass heat capacities, $k_{1}$ and $k_{2}$ the conductivities (of respectively polymer 1 and polymer 2 ) and $\phi$ the heat flow exchanged between the polymers and the calender rolls.

The enthalpy of crystallization has been neglected and polymer solidification has been accounted for artificially through the temperature dependence of the viscosity (Arrhenius law) in the whole temperature range (above and below solidification).

Inertia forces are neglected, but gravity forces need to be accounted for in order to ensure that the polymer will fall from the die on the bottom roll and will exit the contact on the bottom roll.

The interface conditions on $\Gamma$ (équation 12) induces classically that $\eta_{1} \boldsymbol{\varepsilon}_{1}(v) . \mathbf{n}=\eta_{2} \boldsymbol{\varepsilon}_{2}(v) \cdot \mathbf{n}$. As a consequence, there is a jump for the tangential and normal components of the rate of deformation along the interface.

The interface thermal conditions (equation 8 ) on $\Gamma$ induce classically a perfect thermal contact between each polymer. We impose a very important heat transfer coefficient $h_{T} *$ along the surface of the rolls resulting in an interface temperature close to the roll temperature. In zone A a weak convective heat transfer coefficient $\left(h_{T}=10 \mathrm{~W} / \mathrm{m}^{2}{ }^{\circ} \mathrm{C}\right)$ is imposed on both surfaces of the coextruded sheet. In zones B and D the weak convective heat transfer coefficient is imposed on the upper surface and $h_{T} *$ on the bottom surface.

One needs local mesh refinement (see Figure 14) in order to capture precisely the location of the interface and the temperature, strain and stress histories along this interface and also to impose high heat transfer coefficient along the two rolls. The corresponding computational time is very high (a few weeks on a standard PC).

The pressure distribution, uniform through the thickness, within the calender nip is shown on Figure 16 (only one Newtonian polymer is considered in that case). The pressure 
trace (Figure 16) is very similar to the one obtained when using the so called lubrication approximations (Agassant and Avenas, 1977).

The global temperature field is presented on Figure 17 for a roll velocity of $2 \mathrm{~m} / \mathrm{min}$, under steady-state operation. One observes that it is not symmetric at the inlet because the rheologies of the two polymers are not identical and because the coextruded film enters the calender nip on the bottom roll. The temperature field along the interface is shown on Figure 18 for the two roll velocities. It is qualitatively identical to that of Figure 12: Polyamide will crystallize before the nip entrance and polypropylene will crystallize just at the bank entrance at $2 \mathrm{~m} / \mathrm{min}$ and in the nip at $6 \mathrm{~m} / \mathrm{min}$. The temperature profile at nip exit is indicated on Figure 19. One observes again that an important portion of the film thickness remains in the liquid state, even at $2 \mathrm{~m} / \mathrm{min}$. This may induce a real "squeeze flow" in the width direction which cannot be captured by this 2D model.

The shear-rate field is drawn on Figure 20 for the same conditions: on the upper half side the values are first positive and then become negative, which corresponds qualitatively to the results of the early calendering models; the opposite may be observed on the lower half side. The absolute values are not symmetric, which is linked to the different rheologies of polyamide and polypropylene. The trace of the shear rate at the interface is indicated on Figure 21. It is to notice that it does not become zero when the polymer is solidified because an Arrhenius dependence of the viscosity has been used in the whole temperature range (above and below the crystallization temperature). Nevertheless one observes that polypropylene at the interface is subjected to low shear rates and on a very short distance at low roll velocity, as it is subjected to quite high shear rates ( till 120s-1) on a much more important distance at high roll velocity. 
As polyamide is solidified as soon as it is in contact with the bottom roll, the interface velocity is equal to the bottom roll velocity and there is no elongation rate strictly at the interface.

\section{Contribution of the models to the understanding of adhesion mechanisms}

At a first glance, one may believe that calendering will improve adhesion properties of the coextruded product. In fact, as pointed out on figure 3, calendering does not improve the peeling force at low roll velocity and only slightly improves it at high roll velocity.

On one hand, the density of chemical links is always higher in calendering situations than in cast film situations (but less than the saturation level which is observed at die exit). On the other hand the structure of the polypropylene layer and the crystallinity rate is different when the calender is open and when it is closed, and is also influenced by the roll velocity.

These two phenomena depend on the thermo-mechanical history. As pointed out in the successive models, temperature along the interface between the coextruded products depends on the roll velocity. The temperature field within the thickness of the product and especially in the polypropylene layer varies significantly between calendering conditions and cast film conditions. In the same way, there is no strain, nor stress along the interface in cast film conditions, as shear strains and shear stresses are present in calendering and influenced by the conditions in two ways: shear strains increase with the roll velocity (Figures 21 ) but also the distance before solidification at the interface.

The copolymerisation reaction depends on the temperature and strain history but the calendering process represents only a small sequence of this whole history. The residence time in the die \& feedblock ( $>1 \mathrm{~min}$ ) is important and so the maximum density of chemical links is always reached at die exit $\left(\Sigma=0.008 \mathrm{ch} / \mathrm{mm}^{2}\right)$ (Bondil, 2006). The residence time downstream the die (along the stretching path and in the calender before cristallization of both 
polymers) is much shorter (a few seconds depending on the processing conditions). In that flow region, two phenomena are in competition at the interface: the dilution of the copolymer during the short stretching step in air (this leads to decrease the density of chemical links) and an additional copolymerization reaction related to the diffusion (and the convection under shear and elongation) of non reacted PP grafted chains towards the new interface. It is difficult to balance these opposite phenomena and some explanations have been brought by Bondil (2006) and Barraud (2009). In these experiments, the dilution phenomenon is more important than the over-copolymerization reaction as the final density of chemical links is always lower than at die exit. It is to notice that dilution is proportional to the stretching rate which may vary slightly from one experiment to another in order to adjust the calender rate to the extrusion rates. In the calender itself, polyamide will be solidified almost instantaneously and the crosslinking reaction can only proceed on the polypropylene side. The reaction will slow down but can continue up to the beginning of PP crystallization. The density of chemical links is always more important in calendering conditions than in cast film conditions (Figure 4). This may be explained by the existence of shear strains around the interface in calendering conditions which will induce diffusion towards the interface and contribute to additional copolymerization reaction. On the other way, there is surprisingly no influence of the roll velocity: when the roll velocity increases, shear rates increase too, but, due to the very fast solidification of the polyamide layer, elongation rates remain nil.

The crystallization kinetics will be directly governed by the thermo-mechanical history in the calender and, for a lesser extent, by the elongation rate along the stretching path. At low roll velocity, temperature quickly decreases at the interface and polypropylene is subjected there to shear stresses but only during a short period. Within the thickness, temperature decreases less rapidly than at the interface (and even crystallization is not achieved at the calender exit (Figure 12 and Figure 19) and so an important fraction of the polypropylene 
layer is subjected to strains and stresses till the calender exit (Figure 20). Crystallinity is high (higher than 30\%) and the size of the spherulites is small which induces an important yield stress for the polypropylene layer and a high "apparent" peeling stress. At high roll velocity, temperature decreases less quickly along the interface and polypropylene is subjected there to important stresses on a longer distance (but not necessarily on a longer period of time). On the other hand, the temperature decrease is less important within the whole polypropylene thickness and most of the solidification will occur after the calendering step, i.e. in pure cooling conditions (Figure 13): crystallinity is lower (less than 30\%) and the size of the spherulites is much more important which induces a less important yield stress and a lower apparent peeling stress.

In cast film conditions, crystallization will be only influenced by the cooling rate which is more homogeneous than in calendering conditions due to heat transfer convective conditions at the upper surface of the sample.

\section{Conclusion}

The calendering step was supposed to improve both the surface quality and the adhesion properties of the coextruded product. For the Polyamide 6/ Polypropylene system and the process conditions we have investigated, we observe only a weak influence of the process conditions on adhesion. The different models provide interesting figures (temperature, pressure, shear and elongation fields at the interface between the two layers) which contribute to explain qualitatively most of these experimental features. The density of chemical links at the interface is higher in calendering conditions than in cast film conditions and this is related to the additional copolymerization reaction induced by shear rate histories along the interface before polypropylene crystallization. The roll velocity does not influence this density of chemical links. In fact the PA6 layer solidifies quasi instantaneously when it is in contact with 
the bottom roll and there is no elongation any more whereas shear rates are significantly different and this is a proof that elongation is the dominant factor influencing the overcopolymerization reaction. On the other way, roll velocity does influence the thermomechanical history (temperature rate, strain and stress) in the whole polypropylene thickness and so the morphology (crystallinity as well as size of the spherulites) and the mechanical properties of the polypropylene layer. There is no evidence of morphology evolutions within the polyamide 6 layer. As a consequence, in the different processing conditions we have investigated, the peeling force is more dependent on the mechanical properties of the polypropylene layer than on the density of chemical links. In other processing situations, the balance between density of chemical links and structure of the polypropylene layer may be different. This will be the subject of further experiments.

\section{Bibliography}

Agassant, J.F., Avenas P.,"Calendering of P.V.C., Prediction of stress and torque”, J.Macromol. Sci. Phys., B14, 345-365 (1977),

Agassant, J.F., Espy M., “Theoretical and experimental study of the molten polymer flow in the calender bank", Polym. Eng. Sci., 25, 118-121 (1985),

Ardichvili, G., "An attempt of a rational determination of the cambering of calender rolls", Kautschuk ,14, 23-25 and 41-45 (1938),

Arnold, D.N., Brezzi, F., Fortin, M., “A stable finite element for the Stokes equations”, Calcolo, 21, 337-344 (1984),

Barraud, T., « Caractérisation de la formation de copolymères diblocs promoteurs d'adhésion aux interfaces polyamide6- polypropylène des films coextrudés », Thèse de doctorat, Université PARIS-SUD 11 (2009), 
Béraudo, C., Fortin, A., Coupez, T., Demay, Y., Vergnes, B., Agassant, J.F., “A finite element method for computing the flow of multi-mode viscoelastic fluids : comparison with experiments", J. of Non Newtonian Fluid Mech., 75, 1-23 (1998),

Billon, N., Barq, P., Haudin, J.-M. , "Modelling of the cooling of semi-crystalline polymers during there processing”, Intern. Polym. Proc., 6, 348 (1991),

Bondil, H., «Etude de l'adhésion aux interfaces Polypropylene/Polyamide 6 : rôle des copolymères formés in situ en situation de recuits courts représentatifs des assemblages coextrudés », Thèse de Doctorat, Université Pierre et Marie Curie (2006),

Boucher, E., Folkers, J.P., Hervet,, H., Leger, L., Creton, C., "Effects of the formation of copolymer on the interfacial adhesion between semi-crystalline polymers", Macromolecules, 29, 2,774-782 ( 1996),

Cotto, D., Duffo, P., Haudin, J.M., "Cast film extrusion of polypropylene films”, Intern. Polym. Proc., 4, 103-113 (1989),

Devisme, S., Haudin, J.M., Agassant, J.F., Rauline, D., Chopinez, F., "Numerical simulation of extrusion coating”, Intern. Polym. Proc., 22, 90-104 (2007),

Devisme, S., Haudin, J.M., Agassant, J.F., Combarieu, R., Rauline, D., Chopinez, F., "Adhesion in polypropylene/aluminium laminates made by extrusion coating", J. Appl. Polym. Sci., 112, 2609-2624 (2009),

Duffo, P., Monasse, B. „Haudin, J.M, “Cast film extrusion of polypropylene. Thermomechanical and physical aspects”, J. Polym. Eng., 10, 151-229 (1991),

Fourment, L., Chenot, J.L., “Adaptative remeshing and error control for forming process”, Rev. Eur. Eléments Finis , 3, 247-279 (1994),

Fourment, L., Chenot, J.L., Mocellin, K., "Numerical formulation algorithms for solving contact problems in metal forming simulations”, Int. J. Numer. Meth. Eng. ,46 ,1435-1462 (1999), 
Kiparissides, C., Vlachopoulos, J., "Finite element analysis of calendaring", Polym. Eng. Sci., 16,712-719 (1976),

Luther, S., Meves, D., “Three-dimensional polymer flow in the calender bank", Polym. Eng. Sci., 44, 1642-1647 (2004),

McKelvey, J.M., “ Polymer Processing”, Wiley, New York ( 1962),

Mitsoulis, E., Vlachopoulos, J., Mirza, F., "Calendering analysis without the lubrication approximation”, Polym. Eng. Sci., 25, 1, 6-18 (1985),

Pichelin, E., Coupez, T., "Finite element solution of the 3D mold filling problem for viscous incompressible fluid”, Comp. Meth. Appl. Mech. Eng., 163, 359-371 (1998).

\section{Acknowledgements}

We acknowledge Thomas Barraud, Philippe Restagno and Liliane Léger From "Laboratoire de Physique, Université d'Orsay Paris-Sud" for chemical links density measurements and fruitful discussions. We also acknowledge Jean-Marc Haudin from MINES-ParisTech Cemef and Pierre Lafleur from Ecole Polytechnique de Montréal for careful reading and discussion.

\section{Captions of the figures}

Figure 1: Combined coextrusion-calendering line

Figure 2: Free peeling test

Figure 3: Influence of the roll velocity on the peeling force for Cast and Calendering conditions ; peel strength is given in N/15mm

Figure 4: Density of chemical links as a function of the line speed Figure 5: Peeling force as a function of the chemical links density

Figure 6: Photography throughout the thickness of the coextruded film at $2 \mathrm{~m} / \mathrm{min}$; calender closed: the Polyamide 6 layer is in the middlet; the tie layer is on its left with distinct 
spherulites; polypropylene is on the left with decreasing spherulite size from the interface to the core

Figure 7: same roll velocity as figure 6 but the calender is open

Figure 8: calender closed, roll velocity 6m/min: (right) cut through the thickness; (left) core of the polypropylene layer with well defined spherulites

Figure 9: same roll velocity as figure 8 but the calender is open

Figure 10: Flow domain for the finite element computation

Figure 11: Sketch of figure 10 for the multilayer thermal model

Figure 12: Temperature field along the calender at various positions within the coextruded sheet thickness ( roll velocity $2 \mathrm{~m} / \mathrm{min}$ )

Figure 13: Temperature field along the calender at various positions within the coextruded sheet thickness (roll velocity $6 \mathrm{~m} / \mathrm{min}$ )

Figure 14: (up) sketch of the global computation domain: the coextrusion die on the left, (down) detail of the mesh within the nip; polypropylene is red and polyamide is green Figure 15: Pressure field within the calender nip: calender gap =0,8 mm; bank dimension $=2 \mathrm{~mm} ;$ roll velocity $=3.3 \mathrm{~m} / \mathrm{mn} ;$ viscosity $($ Newtonian behaviour $)=476$ Pa.s

Figure 16: Pressure trace along the roll (same data as in figure 15)

Figure 17: Temperature field between the rolls (velocity $2 \mathrm{~m} / \mathrm{min}$ )

Figure 18: Temperature field along the interface for two roll velocities

Figure 19: temperature profile at nip exit for the two calendering conditions

Figure 20: Shear rate field between the two rolls (velocity $2 \mathrm{~m} / \mathrm{min}$ )

(grey colour is up 25s-1)

Figure 21: Shear rate distribution along the interface for two roll velocities 


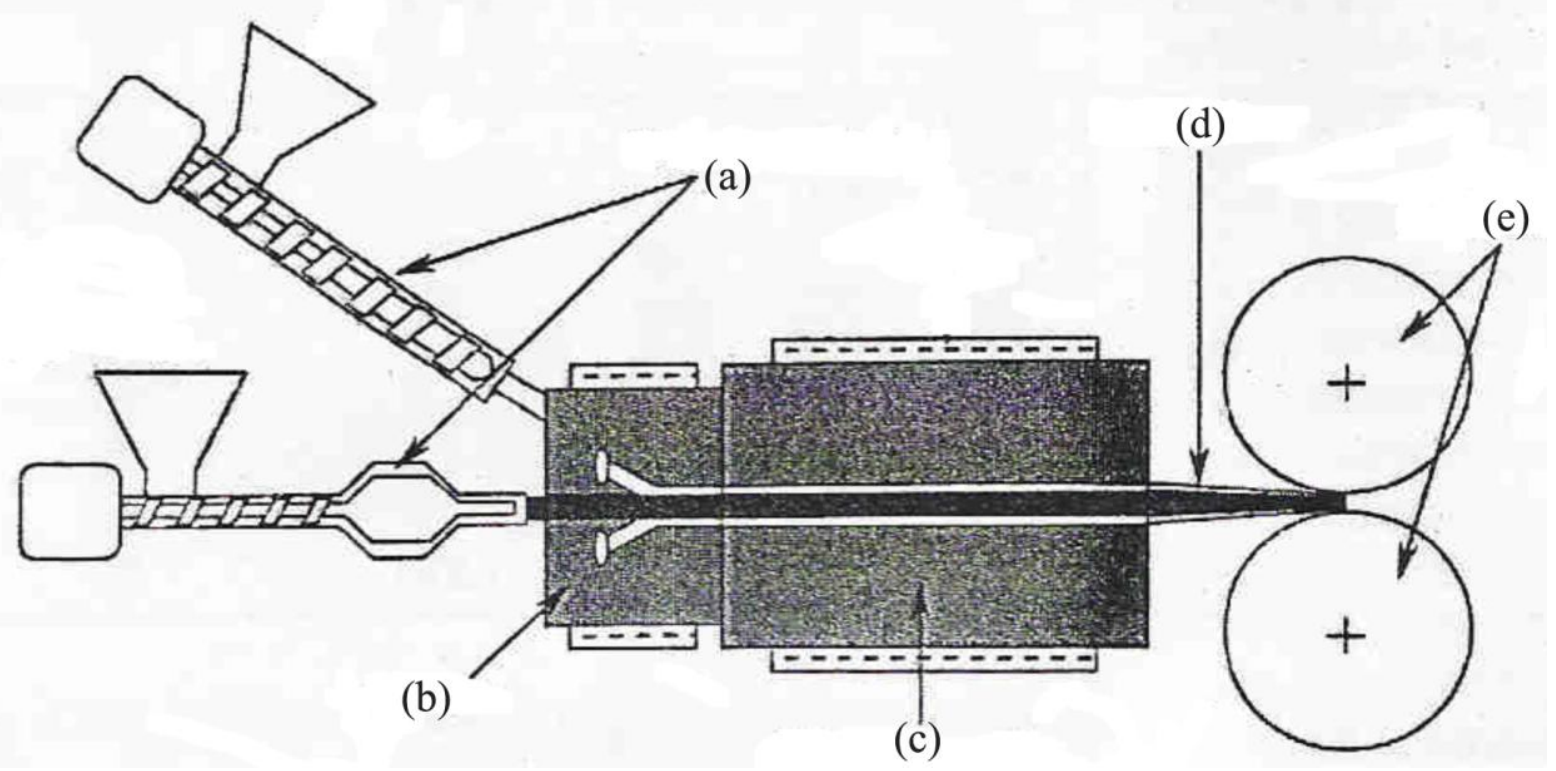

Fig 1: Combined coextrusion-calendering line

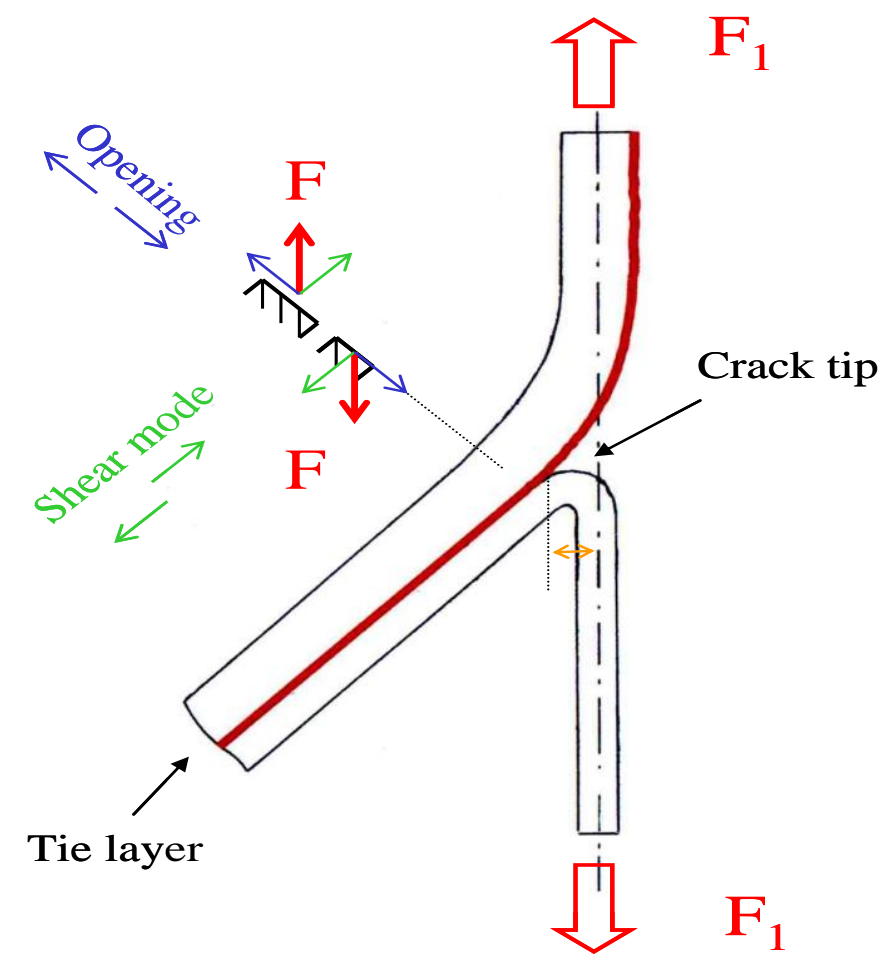

Figure 2: Free peeling test 


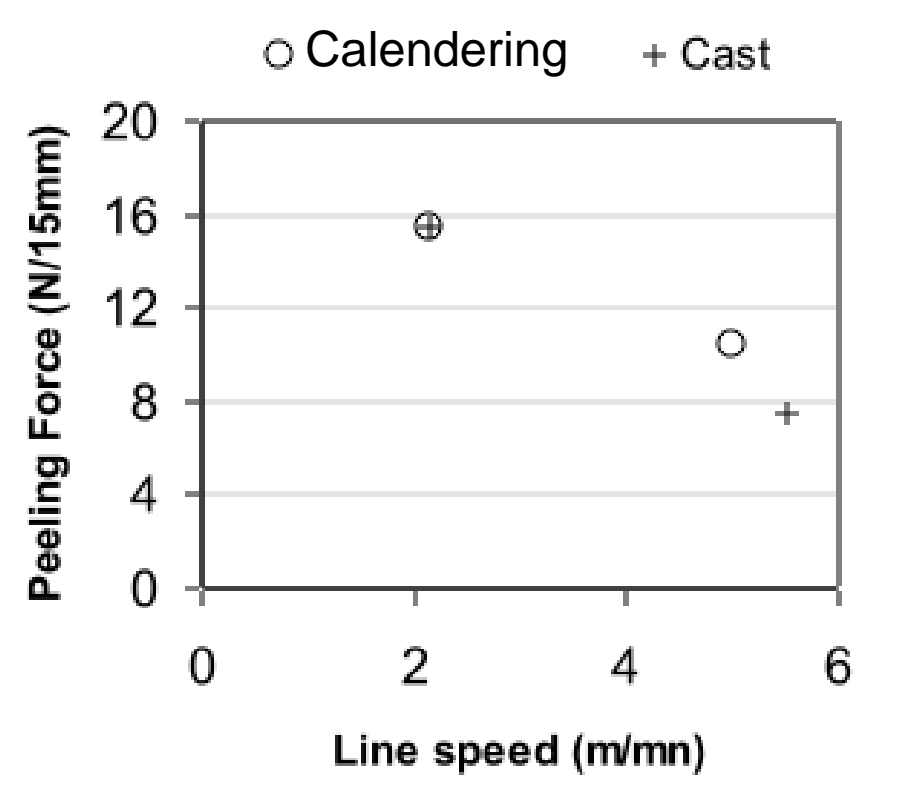

Figure 3: Influence of the roll velocity on the peeling force for Cast and Calendering conditions ; peel strength is given in $\mathrm{N} / 15 \mathrm{~mm}$

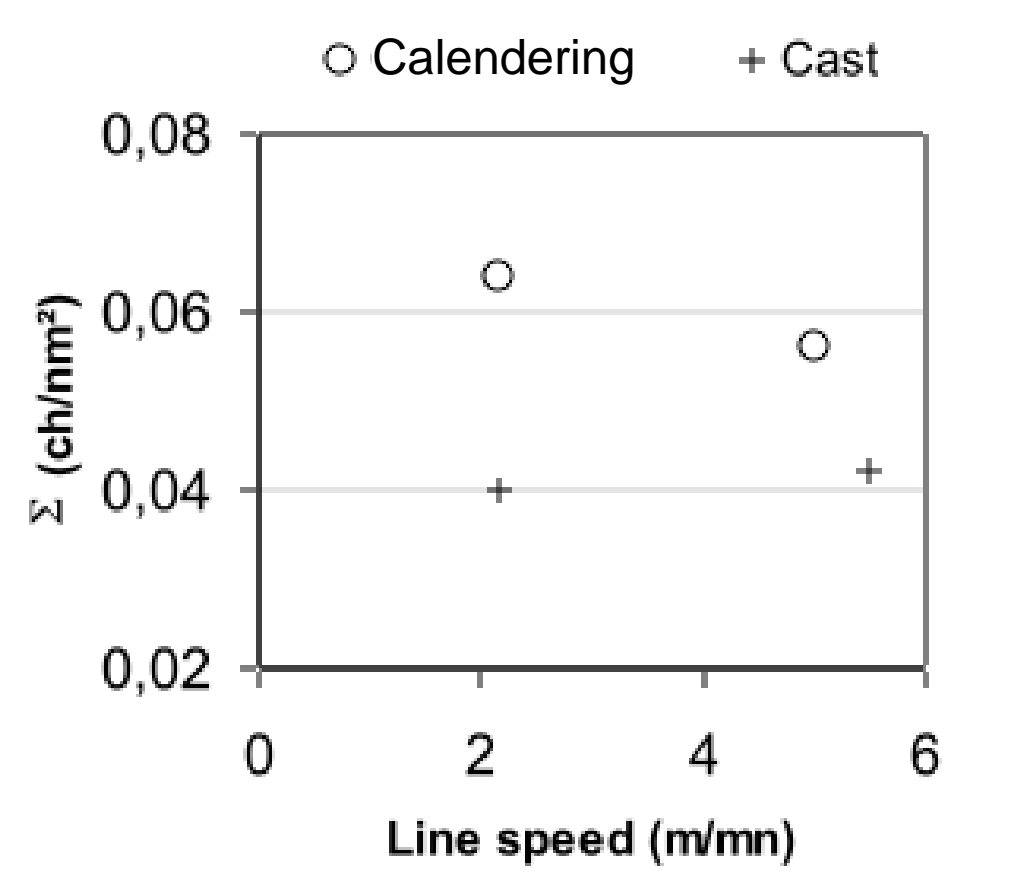

Figure 4: Density of chemical links as a function of the line speed 


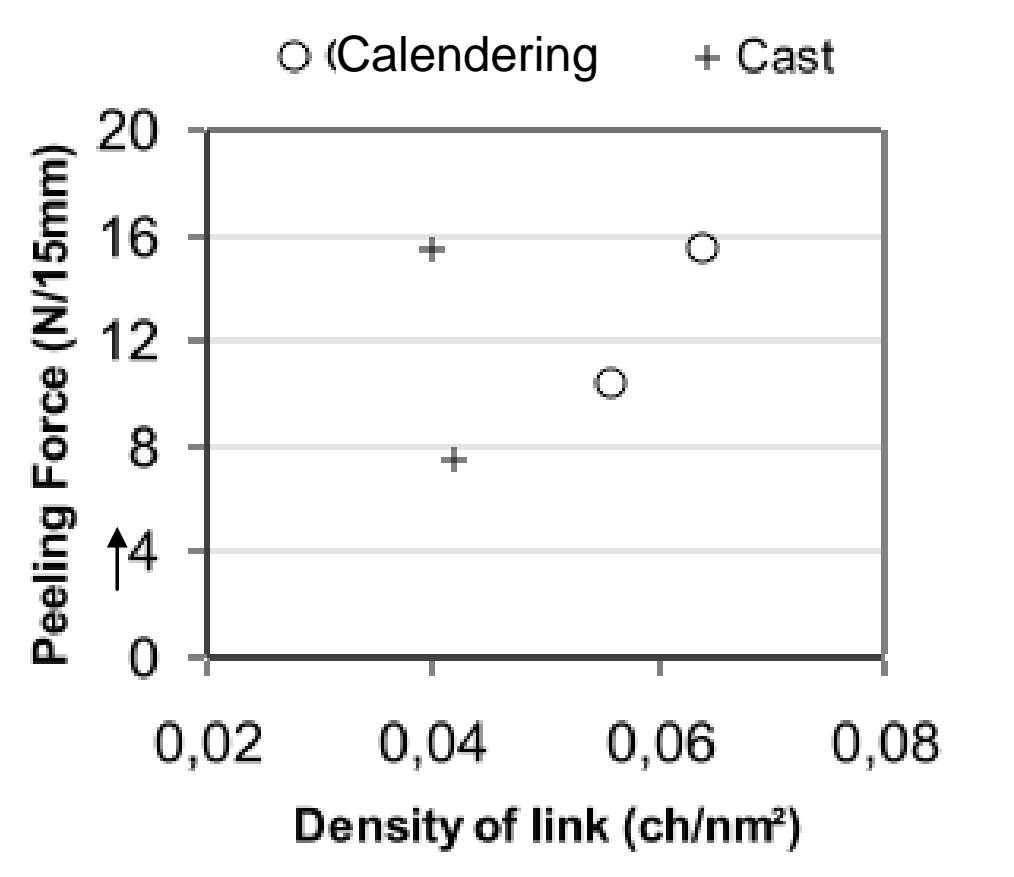

Figure 5: Peeling force as a function of the chemical links density

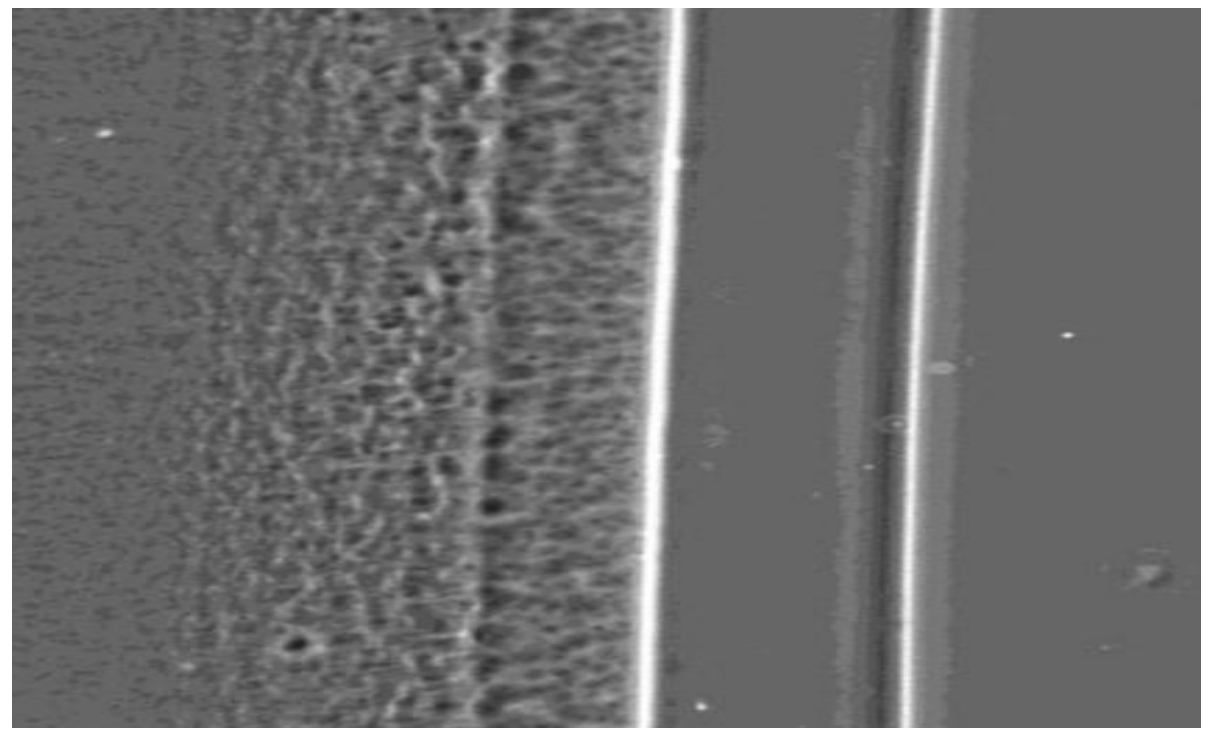

Polypropylene tie-layer polyamide 6

Figure 6: Photography throughout the thickness of the coextruded film at $2 \mathrm{~m} / \mathrm{min}$; calender closed: the Polyamide 6 layer is in the middle; the tie layer is on its left with distinct spherulites; polypropylene is on the left with decreasing spherulite size from the interface to the core 


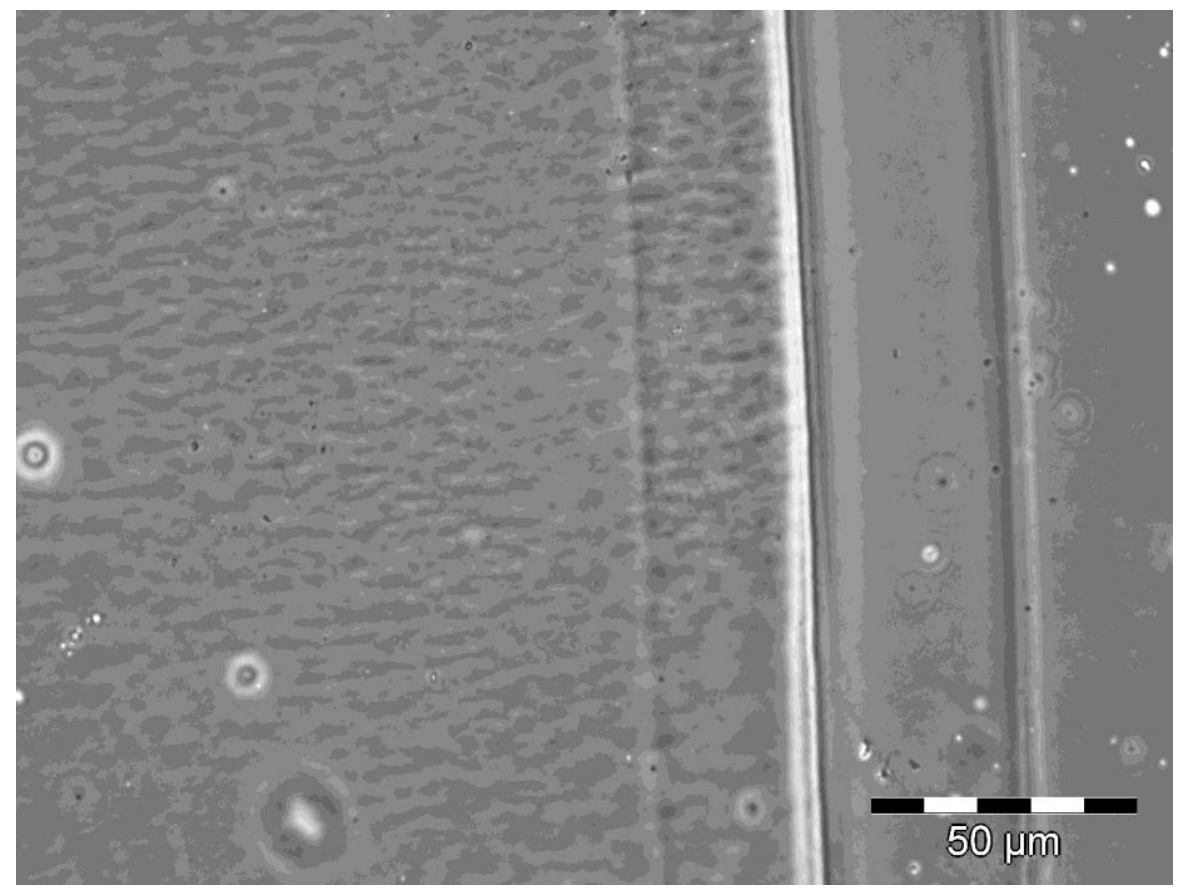

polypropylene tie-layer polyamide 6

Figure 7: same roll velocity as figure 6 but the calender is open

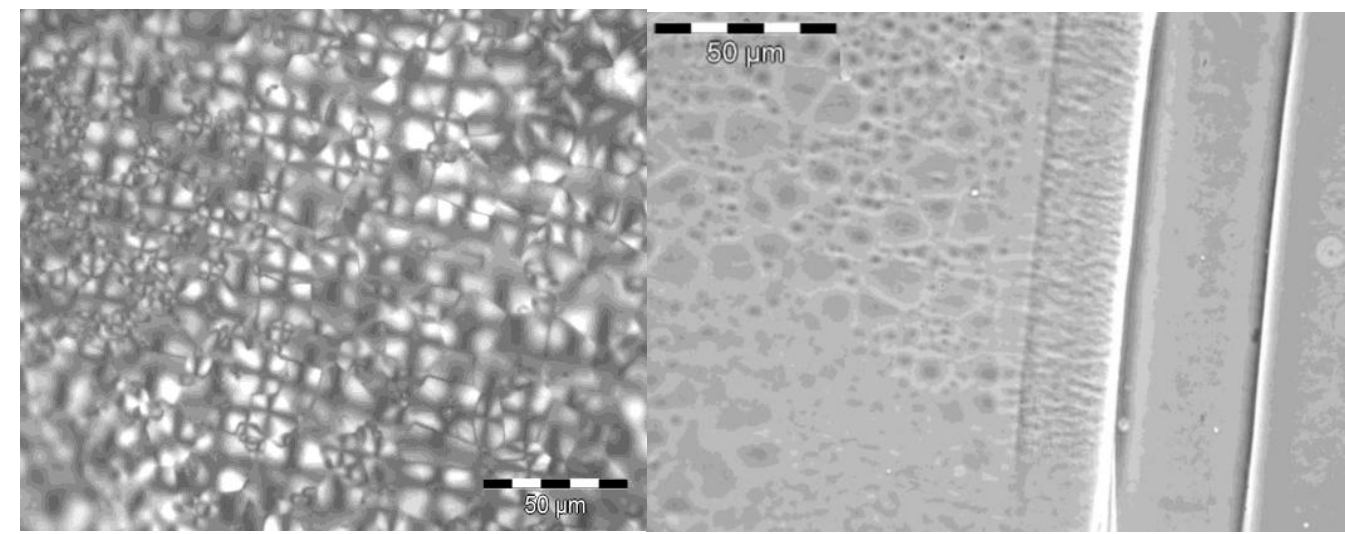

Polypropylene tie-layer polyamide 6

Figure 8: calender closed, roll velocity 6m/min: (right) cut through the thickness; (left) core of the polypropylene layer with well defined spherulites 

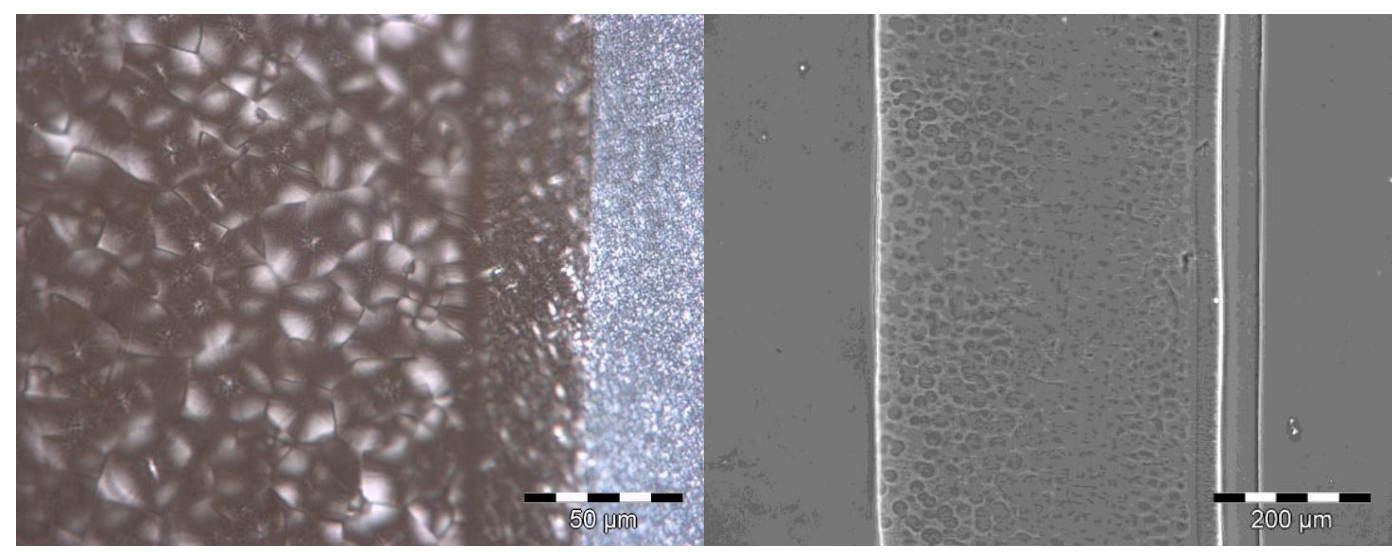

Polypropylene

tie-layer polyamide

Figure 9: same roll velocity as figure 8 but the calender is open (global picture on the righ;t more detailed picture around the interface on the left)

extruder

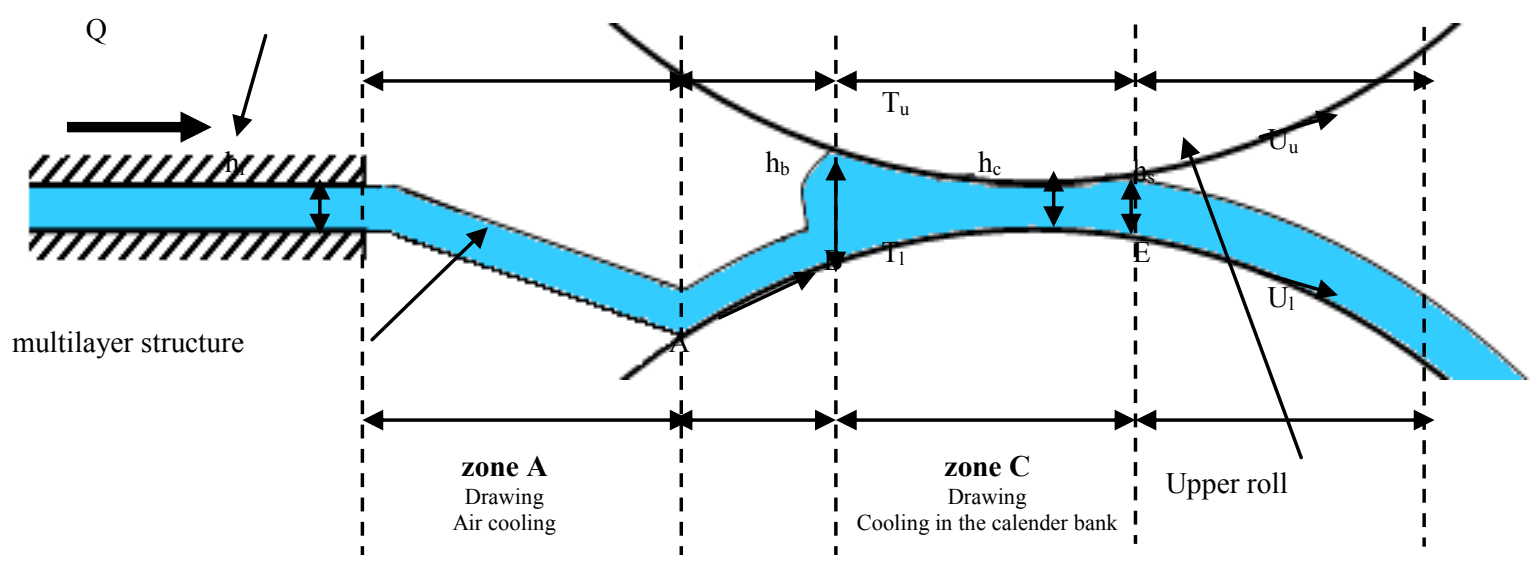

Figure 10: Flow domain for the finite element computation 


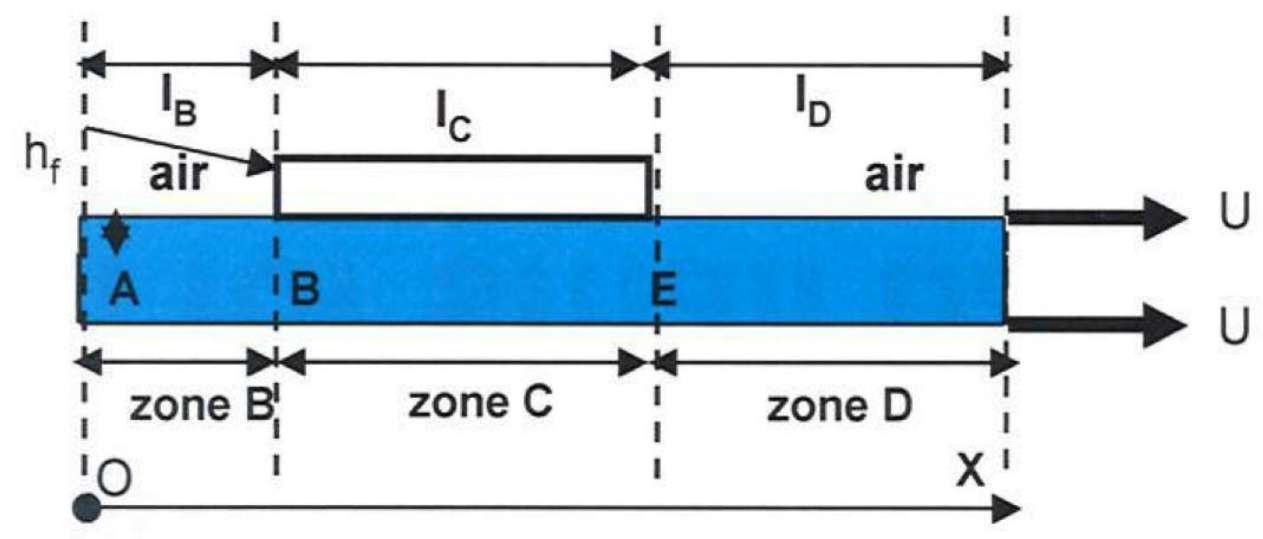

Figure 11: Sketch of figure 10 for the multilayer thermal model

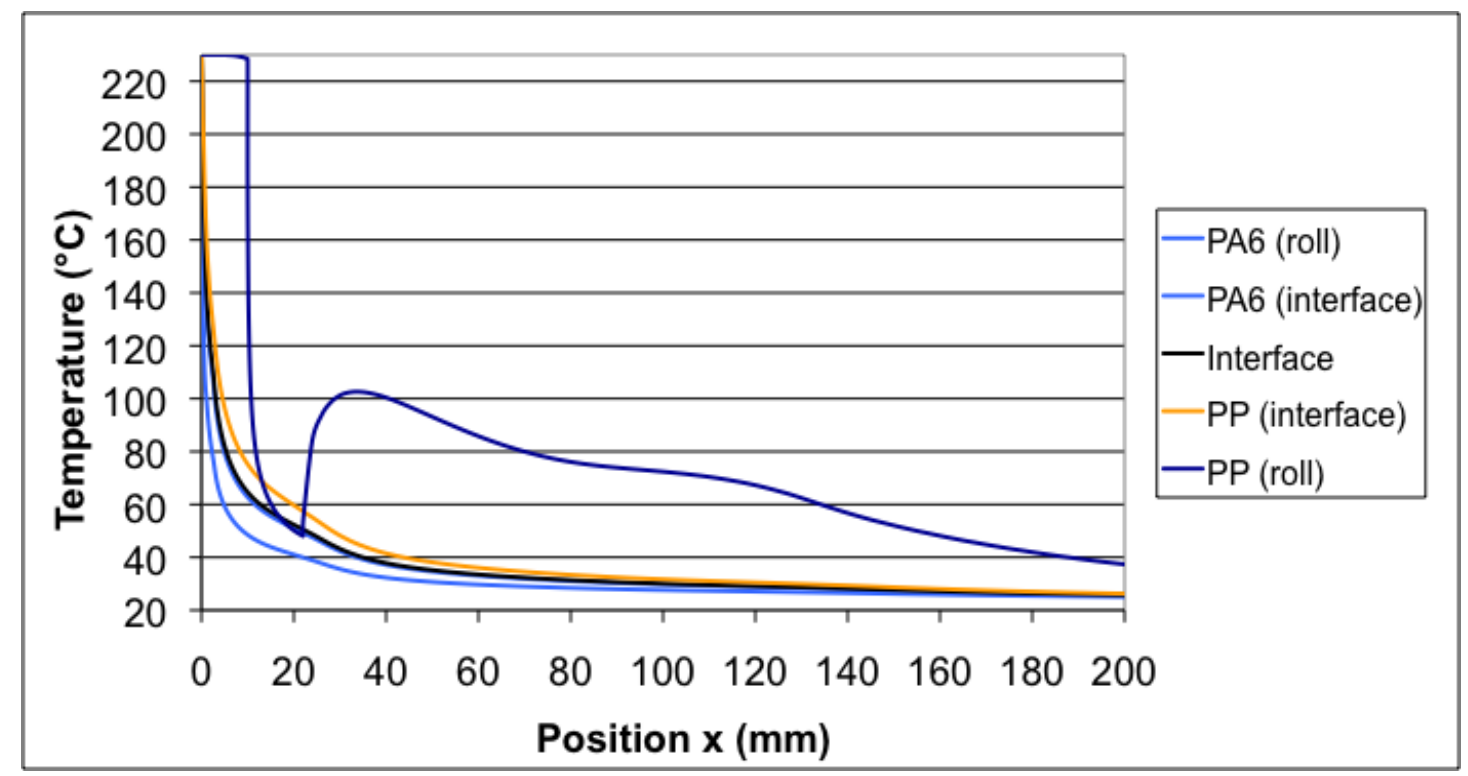

Figure 12: Temperature field along the calender at various positions within the coextruded sheet thickness (roll velocity $2 \mathrm{~m} / \mathrm{min}$ ) 


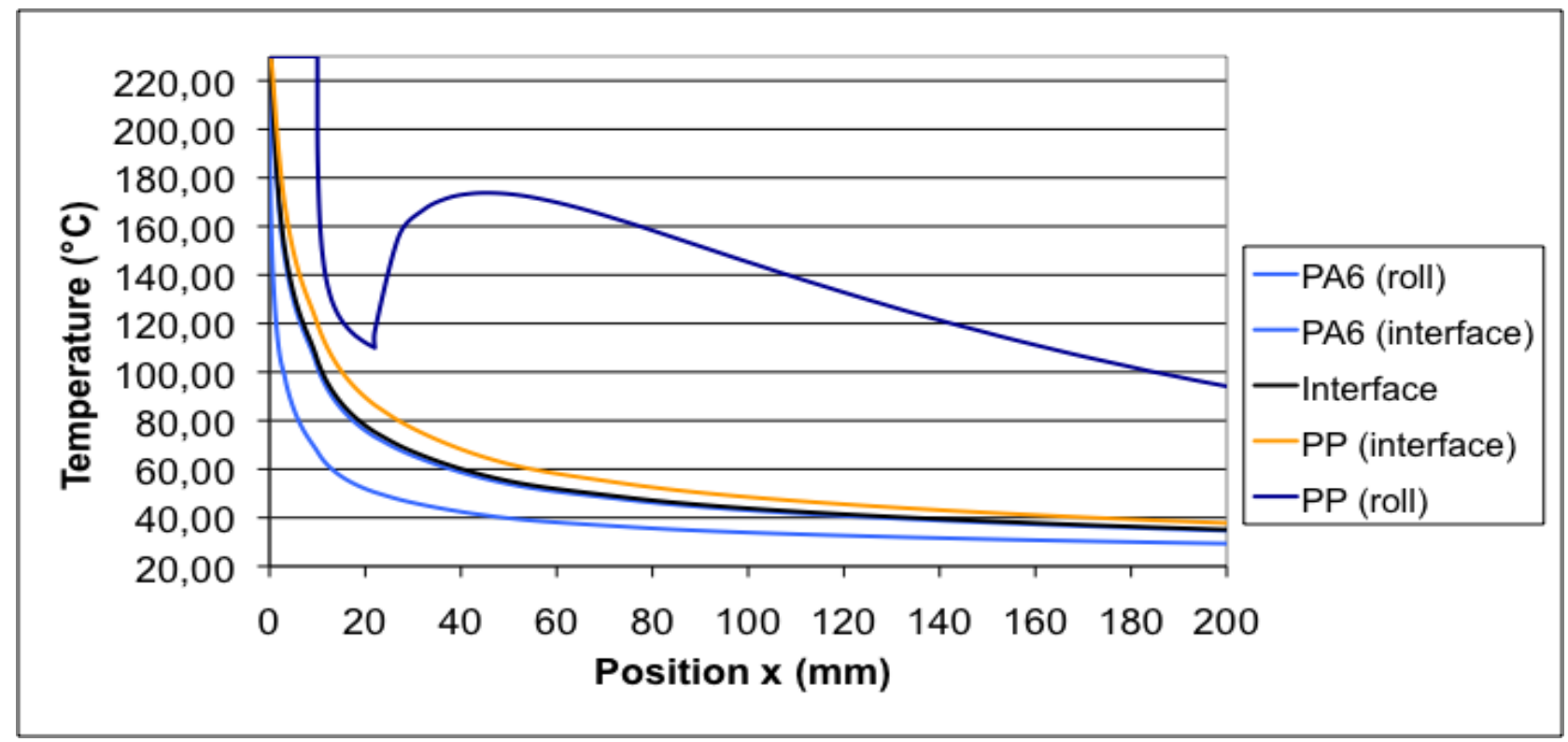

Figure 13: Temperature field along the calender at various positions within the coextruded sheet thickness (roll velocity $6 \mathrm{~m} / \mathrm{min}$ ) 


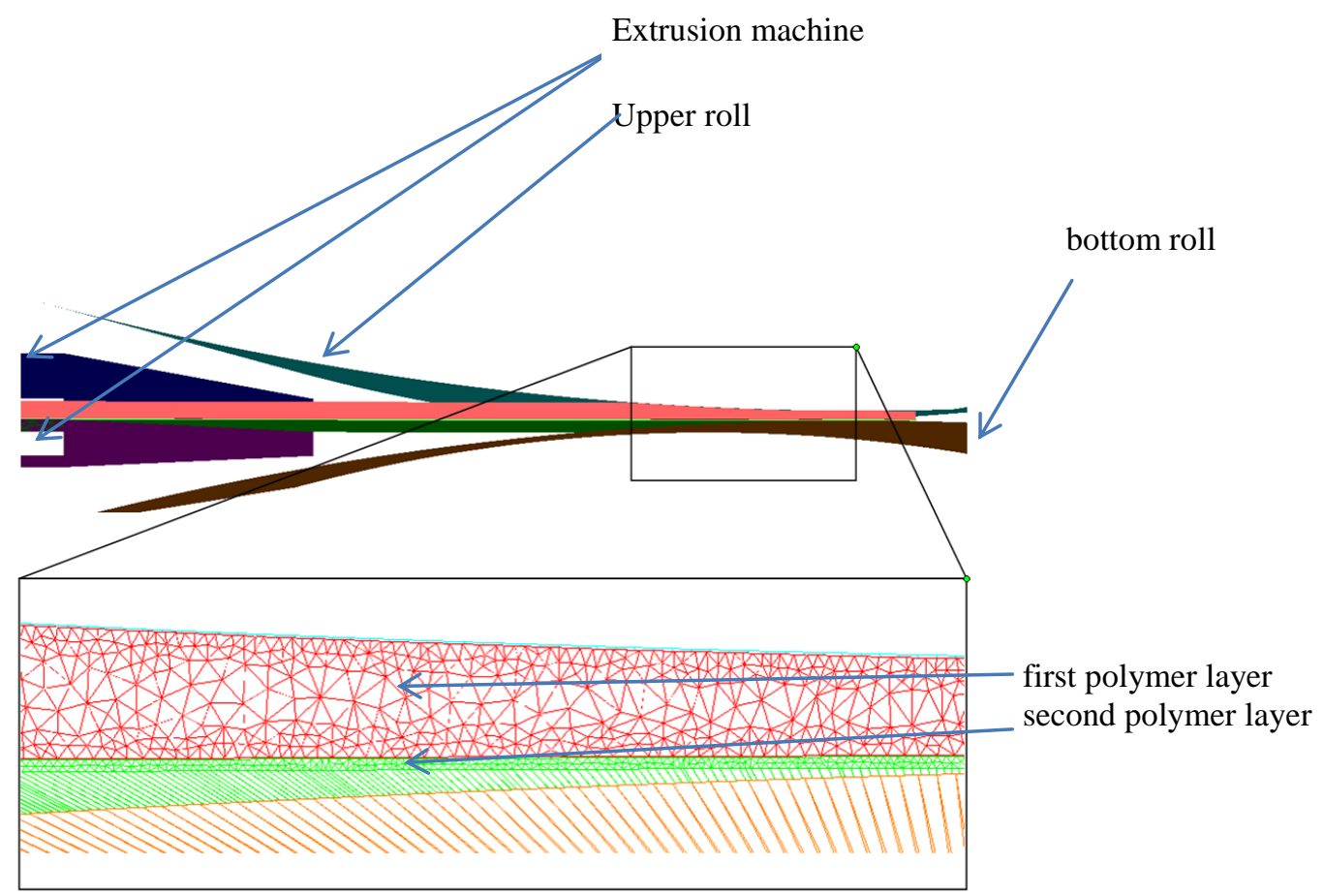

Figure 14: (up) sketch of the global computation domain: the coextrusion die on the left,

(down) detail of the mesh within the nip; polypropylene is red and polyamide is green

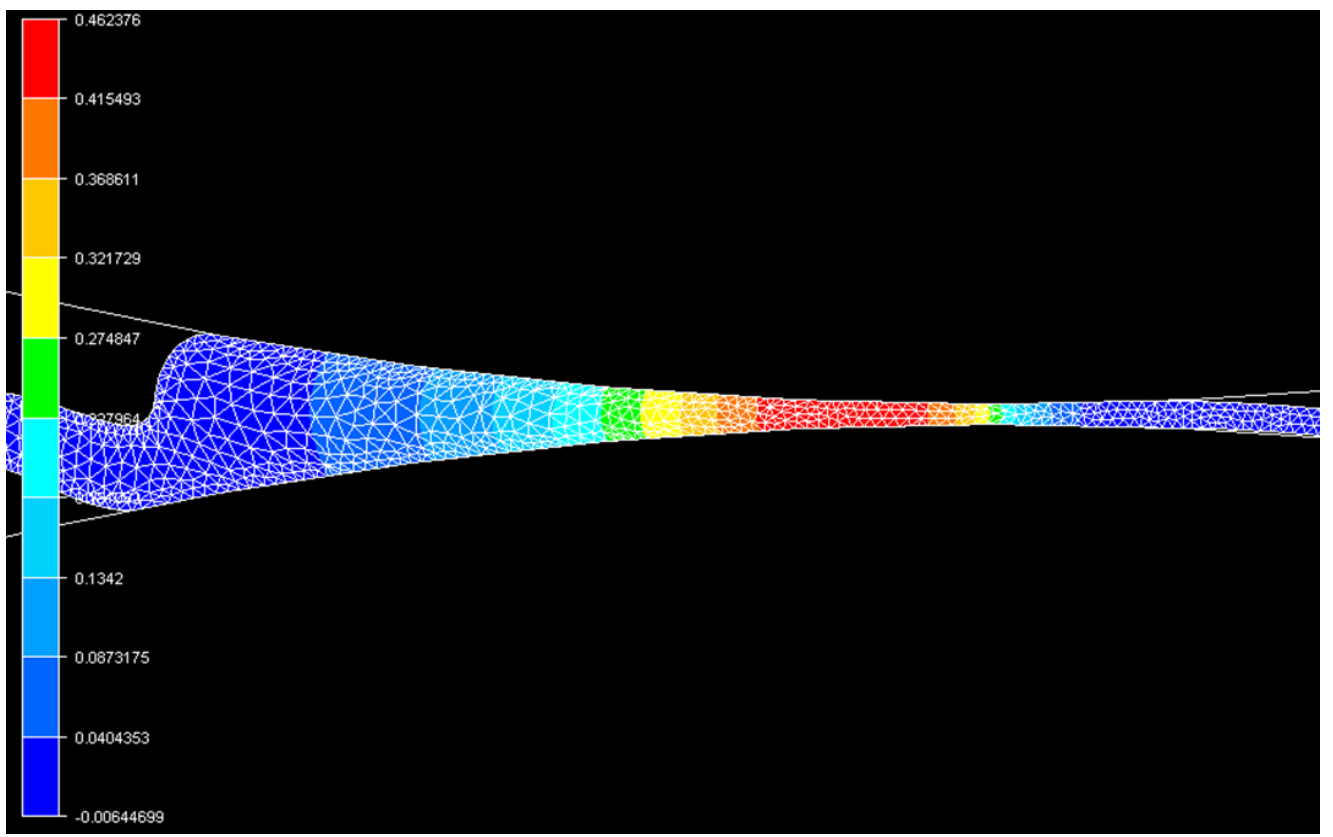

Figure 15: Pressure field within the calender nip: calender gap =0,8 $\mathrm{mm}$; bank

dimension $=2 \mathrm{~mm} ;$ roll velocity $=3.3 \mathrm{~m} / \mathrm{mn} ;$ viscosity $($ Newtonian behaviour $)=476$ Pa.s 


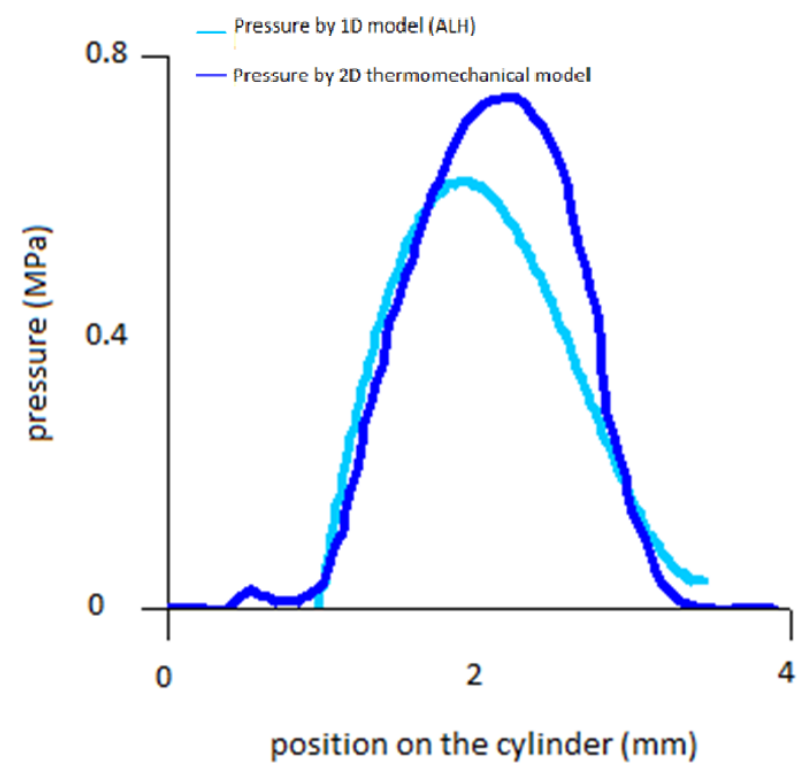

Figure 16: Pressure trace along the roll (same data as in figure 15)

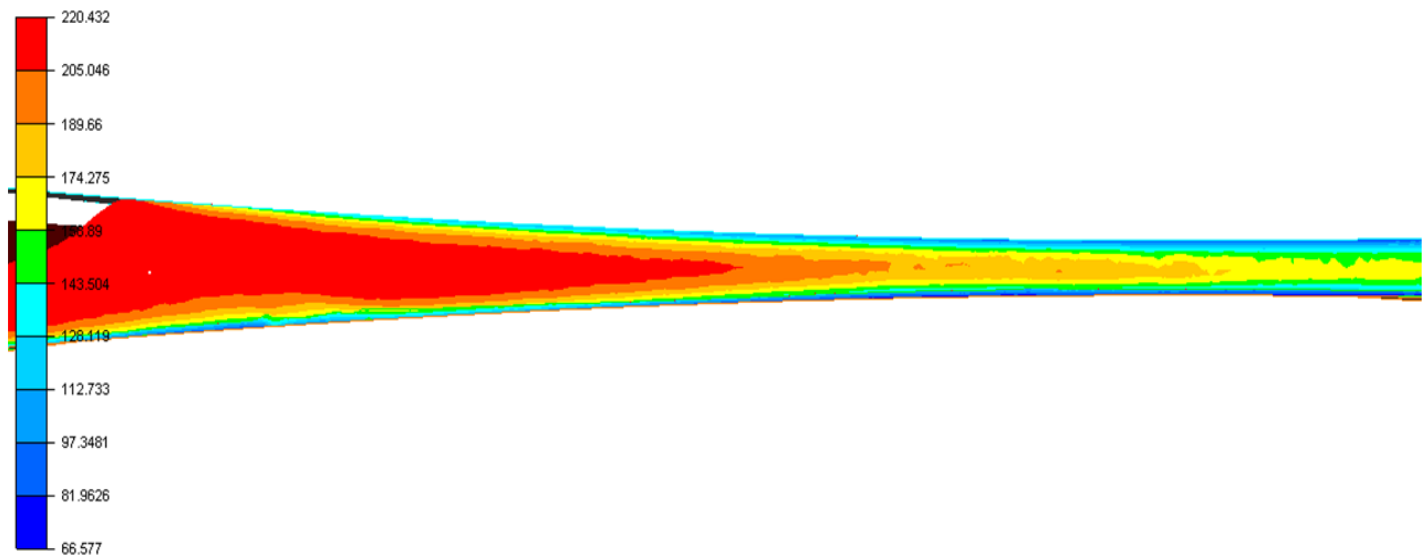

Figure 17: Temperature field between the rolls (velocity $2 \mathrm{~m} / \mathrm{min}$ ) 


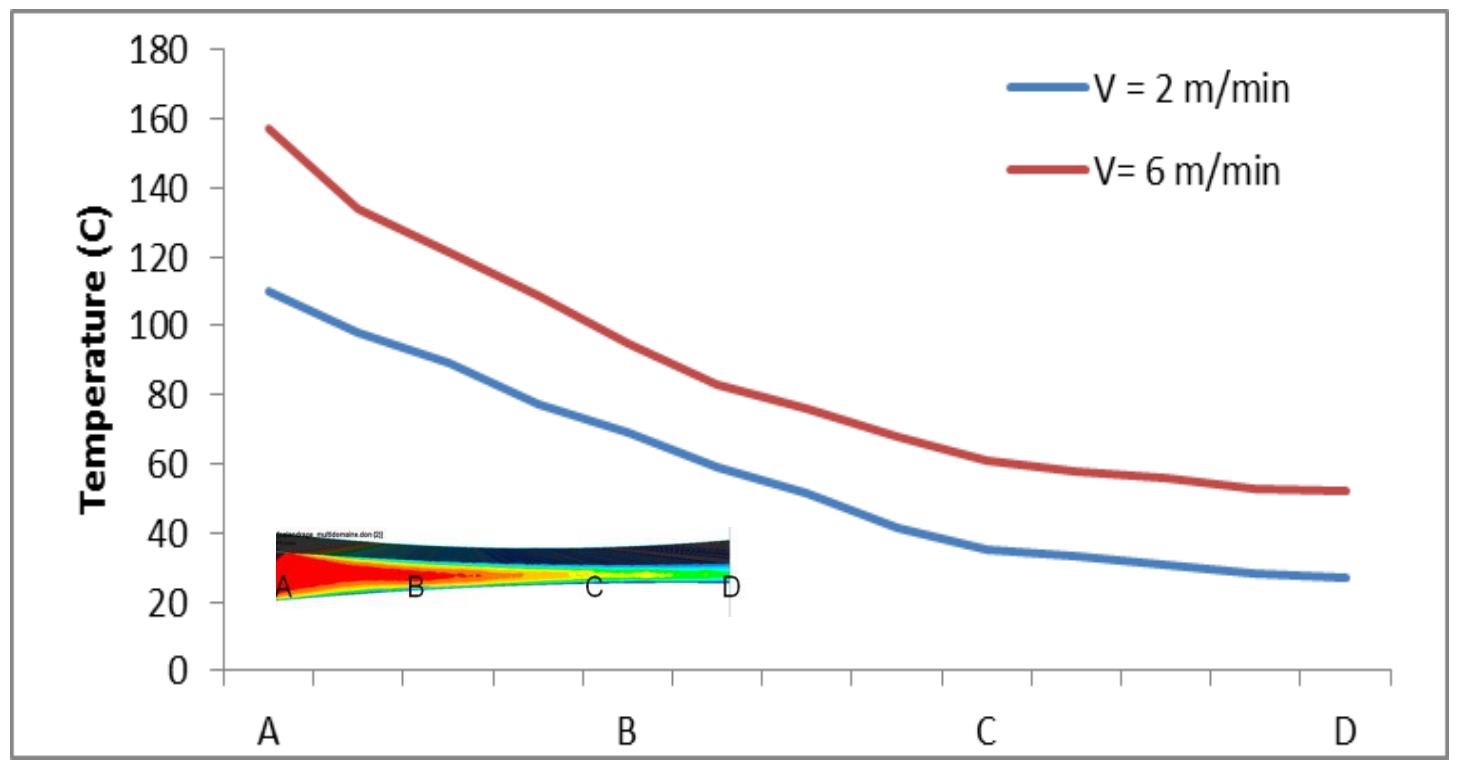

Figure 18: Temperature field along the interface for two roll velocities

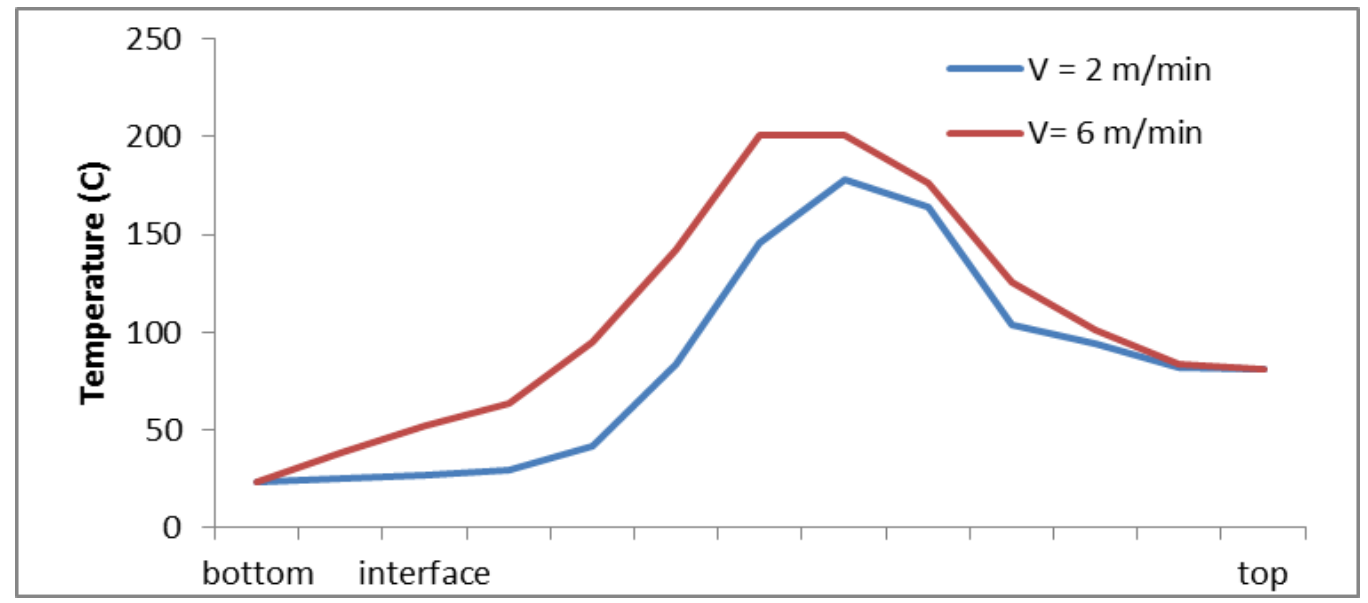

Figure 19: temperature profile at nip exit for the two calendering conditions 


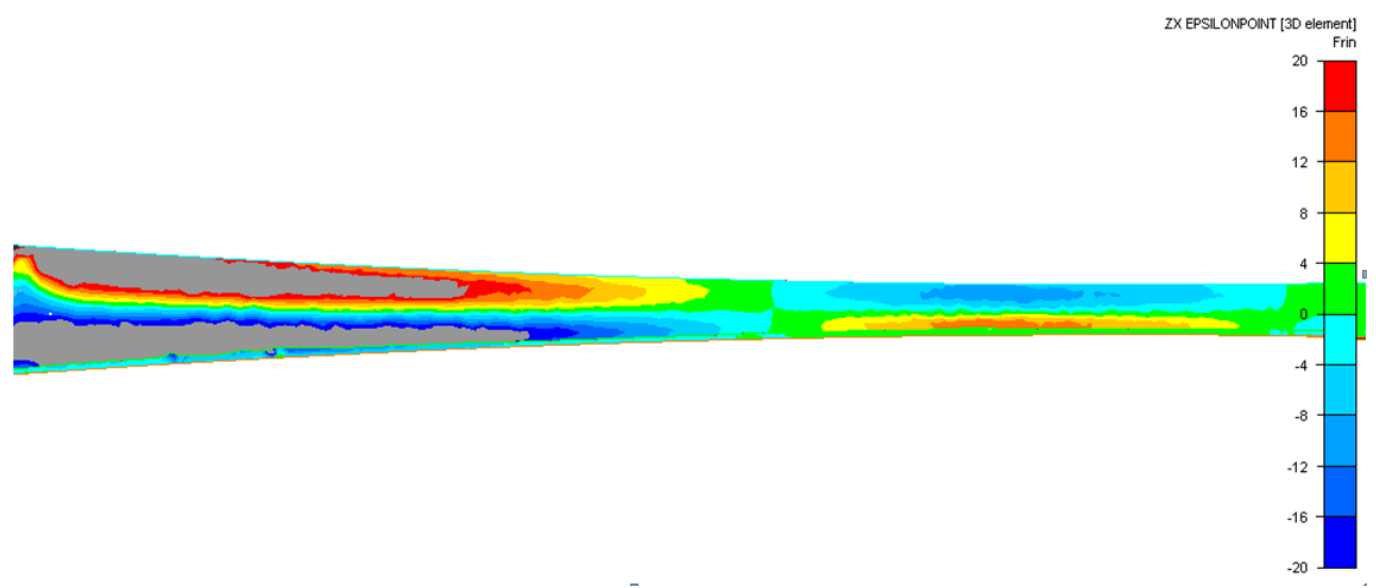

Figure 20: Shear rate field between the two rolls (velocity $2 \mathrm{~m} / \mathrm{min}$ )

(grey colour is up 25s-1)

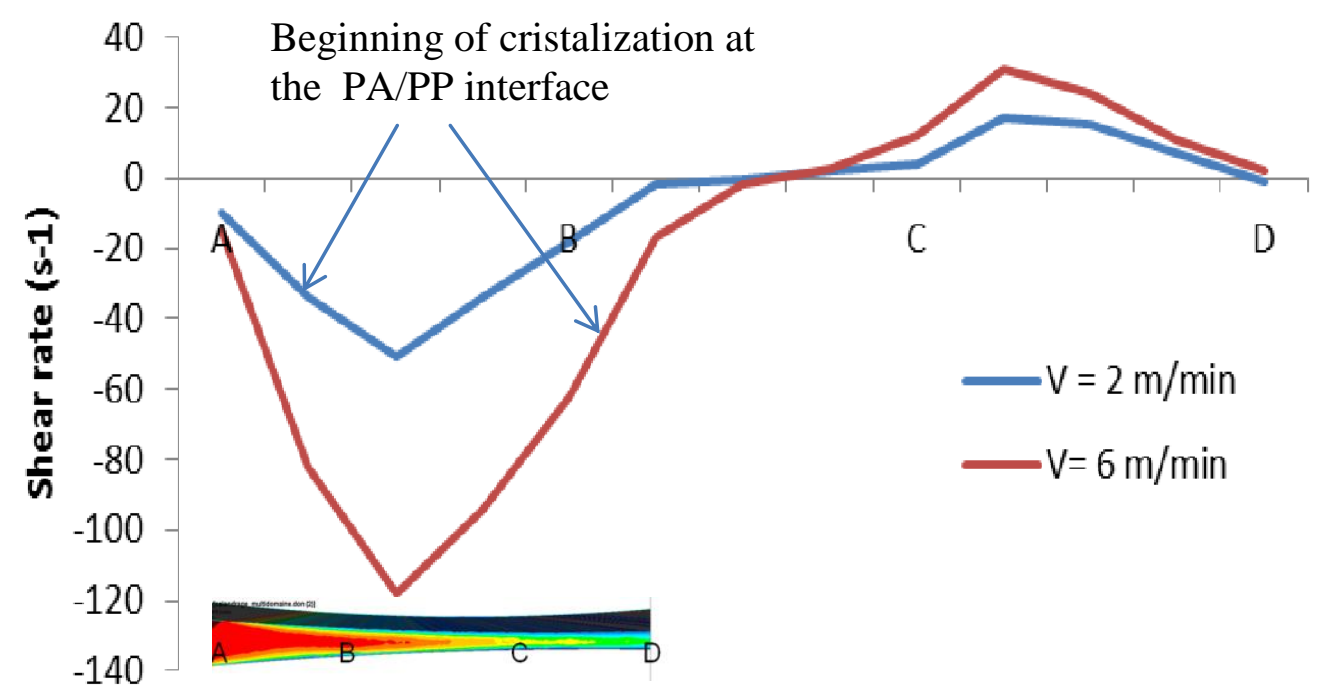

Figure 21: Shear rate distribution along the interface for two roll velocities 